\title{
Sequential Versus Concurrent Chemoradiation Therapy by Surgical Margin Status in Resected Non-Small Cell Lung Cancer
}

\author{
Vivek Verma, MDª Amy C. Moreno, MD; Waqar Haque, MDc; Penny Fang, MD ${ }^{\mathrm{b}}$; \\ and Steven H. Lin, MD, PhD
}

\begin{abstract}
Background: Postoperative chemoradiotherapy (CRT) for non-small cell lung cancer (NSCLC) can be delivered sequentially (sCRT) or concurrently (cCRT). Without high-volume data, current guidelines recommend either option for patients with negative margins (M-) and CCRT for those with positive margins $(\mathrm{M}+)$. In this study, survival was compared between sCRT versus CCRT for $\mathrm{M}-$ and $\mathrm{M}+$ disease; survival in patients who underwent SCRT was also assessed with chemotherapy-first versus radiotherapy (RT)-first. Methods: The National Cancer Database was queried for patients with primary NSCLC undergoing surgery followed by CRT. Patients were excluded if they received neoadjuvant chemotherapy or RT. Both $\mathrm{M}-$ and $\mathrm{M}+$ (including R1 and R2) subcohorts were evaluated. Multivariable logistic regression ascertained factors associated with CCRT delivery. Kaplan-Meier analysis evaluated overall survival (OS); Cox proportional hazards modeling determined variables associated with OS. Propensity score matching aimed to address group imbalances and indication biases. Results: Of 4,921 total patients, 3,475 (71\%) were M-, 1,446 (29\%) were M+, 2,271 (46\%) received sCRT, and 2,650 (54\%) underwent cCRT. Median OS among the SCRT and CCRT groups in patients who were M- was 54.6 versus 39.5 months, respectively $(P<.001)$; differences persisted following propensity score matching $(P<.001)$. In the overall $M+$ cohort, outcomes for sCRT and cCRT were 36.3 versus 30.5 months $(P=.011)$, but showed equipoise following matching $(P=.745)$. In the R1 and R2 subsets, no differences in OS were seen between cohorts $(P=.368$ and .553 , respectively). When evaluating the SCRT population, there were no OS differences between chemotherapy-first and RT-first after matching $(P=.229)$. Conclusions: Postoperative SCRT was associated with improved survival compared with cCRT in patients with $M-$ disease, with statistical equipoise in those with $\mathrm{M}+$ disease. Differential sequencing of SCRT does not appear to affect survival.
\end{abstract}

J Nat/ Compr Canc Netw 2018;16(5):508-516 doi: 10.6004 ljnccn.2018.7007

Despite continual efforts to improve prognosis and decrease treatment-related toxicities, non-small cell lung cancer (NSCLC) remains a major health epidemic worldwide. NSCLC is commonly treated with upfront surgery with or without prior induction chemotherapy, followed by postoperative radiotherapy (PORT) or chemoradiotherapy (CRT). ${ }^{1}$ PORT has been controversial since the results of a meta-analysis showed a survival detriment associated with its use ${ }^{2}$; however, this study was heavily

\footnotetext{
aDepartment of Radiation Oncology, Allegheny General Hospital, Pittsburgh, Pennsylvania; 'bepartment of Radiation Oncology, University of Texas MD Anderson Cancer Center, Houston, Texas; and 'Department of Radiation Oncology, Houston Methodist Hospital, Houston, Texas.

Submitted October 20, 2017; accepted for publication January 23, 2018 Dr. Lin has disclosed that he has received research funding from Elekta, STCube Pharmaceuticals, Peregrine, Bayer, and Roche/Genentech; has served as a consultant for AstraZeneca; and has received honorarium from US Oncology and ProCure. The remaining authors have disclosed that they have no financial interests, arrangements, affiliations, or
}

criticized regarding the patient population, inclusion of outdated radiotherapy (RT) techniques, and allowance of high RT doses (both total and fractional). Further definition of optimal PORT subgroups occurred with a pivotal publication showing benefit for patients with $\mathrm{pN} 2$ disease and those with $\mathrm{pN} 1$ disease not receiving chemotherapy ${ }^{3}$; this has since been corroborated by large-volume retrospective studies. ${ }^{4,5}$ PORT is also indicated for suspected or involved surgical margins. ${ }^{1,6,7}$ commercial interests with the manufacturers of any products discussed in this article or their competitors.

Author contributions: Study concept: Verma, Moreno, Fang. Statistical analysis: Moreno, Haque. Supervision: Lin. Manuscript preparation and approval: All authors.

Correspondence: Steven H. Lin, MD, PhD, Department of Radiation Oncology, The University of Texas MD Anderson Cancer Center, 1515 Holcombe Boulevard, Unit 097, Houston, TX 77030.

Email: shlin@mdanderson.org 
However, what remains unclear in light of these data is optimal sequencing of postoperative RT and chemotherapy. Randomized studies have not shown a benefit in local control or survival for postoperative CRT versus PORT alone. ${ }^{8}$ Although clear evidence in unresected NSCLC shows that concurrent CRT (cCRT) produces improved outcomes at the expense of greater toxicities, ${ }^{9,10}$ phase II studies of postoperative cCRT have observed encouraging toxicity profiles. ${ }^{11,12}$ Sequential CRT (sCRT) remains theoretically appealing given the relative fragility of the postoperative setting, during which serious toxicities could develop if cCRT is delivered.

Currently, this notion remains highly controversial. National guidelines exemplify this ambiguity, recommending either paradigm for patients with margin-negative $(\mathrm{M}-)$ and margin-positive $(\mathrm{M}+)$ $\mathrm{R} 1$ (microscopic) disease; cCRT is endorsed for R2 (gross residual) disease. ${ }^{1}$ Additionally, sequencing of sCRT is also highly controversial. ${ }^{13}$ Chemotherapy followed by RT may allow for earlier treatment of potential micrometastases, ${ }^{3}$ but others espouse initial RT so as to deliver early local therapy to the area of greatest disease burden. ${ }^{14}$

To date, evaluation of sCRT versus cCRT by margin status, as well as optimal sequencing of sCRT, have not been studied with high-volume data. This study of a large, contemporary national database aimed to evaluate national practice patterns and outcomes addressing these important and highly applicable clinical questions.

\section{Methods}

The National Cancer Database (NCDB) is a joint project of the Commission on Cancer $(\mathrm{CoC})$ of the American College of Surgeons and the American Cancer Society, and consists of deidentified information regarding tumor characteristics, patient demographics, and patient survival for approximately $70 \%$ of the US population. ${ }^{15-24}$ All pertinent cases are reported regularly from $\mathrm{CoC}$-accredited centers and compiled into a unified data set, which is then validated. The NCDB contains information not captured in the SEER database, including details regarding use of systemic therapy. The data used in the study were derived from a deidentified NCDB file (2004-2014). The American College of Surgeons nor the $\mathrm{CoC}$ have not verified and neither are responsible for the analytic or statistical methodology used or the conclusions drawn from these data by the investigators. As all patient information in the NCDB database is deidentified, this study was exempt from Institutional Review Board evaluation.

The inclusion criterion for this study was newly diagnosed, primary NSCLC treated with upfront surgery followed by postoperative chemotherapy and RT. Patients who received neoadjuvant chemotherapy and/or RT were excluded. Surgery was defined as an oncologic-quality procedure, and hence local tumor destruction/excision techniques (including laser, cryosurgery, and electrocautery) constituted exclusion. RT was defined as external-beam RT to a dose of 45 to 74 Gy. ${ }^{5,6}$ Per multiple other NCDB publications, concurrent therapy referred to starting chemotherapy and RT within 14 days of each other, with the remainder designated as sequential. ${ }^{25,26}$ Patients with an interval of $>6$ months from surgery to adjuvant therapy, or between adjuvant RT and chemotherapy, were excluded, per other work, in order to differentiate between potential salvage and definitive therapy. ${ }^{5}$ No patients were excluded who died within a certain point after surgery, similar to prior investigations ${ }^{5}$ and sensitivity analyses demonstrating no impact on results when this cohort was eliminated. ${ }^{6}$ Lastly, although PORT is recommended for $\mathrm{pN} 2$ disease, we allowed $\mathrm{pNO}$ and $\mathrm{pN} 1$ disease for numerous reasons, including the lack of prospective assessment to date on whether these populations are at higher risk of locoregional recurrence; retrospective studies have suggested no differences. ${ }^{27} \mathrm{We}$ also allowed inclusion of patients with $\mathrm{pN} 1, \mathrm{M}$ - disease owing to the lack of direct randomized comparisons between postoperative CRT and chemotherapy alone, together with the fact that PORT is still often delivered in these patients. ${ }^{6} \mathrm{We}$ also allowed patients with $\mathrm{pNO}$, M- disease (which constituted a large minority of this cohort) for multiple reasons. First, postoperative CRT cannot be disregarded altogether for pT3-4, pN0 disease; these cases may still be at enough risk of locoregional failure (eg, based on extent of lymphovascular invasion, lymph node ratio, and other factors) to warrant adjuvant therapy. Additionally, many institutions make individualized decisions on adjuvant local therapy based on precise surgical findings, in light of data showing a connection between local failure and distance from tumor to ink. ${ }^{28,29}$ 
Verma et al

In accordance with the variables in NCDB files, information collected on each patient broadly included demographic, clinical, and treatment data. All statistical tests were 2-sided, with a threshold of $P<.05$ for statistical significance, and were performed using STATA, version 14 (StataCorp LP). Multivariable logistic regression modeling was used to determine characteristics that were predictive for receipt of cCRT. The Kaplan-Meier method was used for survival analysis, and comparisons between groups were performed with the log-rank test. Overall survival (OS) was defined as the interval between the date of diagnosis and the date of death, or censored at last contact. Univariate analysis was performed to determine factors associated with OS, and subsequently Cox multivariate analysis was performed including variables that were either significant or showed a strong trend to statistical significance on univariate analysis. The proportional hazards assumption was checked graphically using log-log plots.

To account for indication bias, propensity score matching (PSM) was used to compare patients between groups. PSM is a method that creates quasicase/control pairs using a retrospective cohort in an effort to account for the recorded and unrecorded confounding variables. ${ }^{30-32}$ Propensity scores were calculated using a multivariable logistic regression model, with the dependent variable being receipt of particular treatment paradigm and the independent variables being those that were statistically significant for correlation with OS on multivariate analysis. Patients were matched 1:1 without replacement

Table 1. Cohort Characteristics and Factors Associated With Receiving Concurrent CRT

\begin{tabular}{|c|c|c|c|c|c|}
\hline \multirow[b]{2}{*}{ Parameter } & \multirow{2}{*}{$\begin{array}{l}\text { All Patients } \\
(\mathrm{N}=4,921)\end{array}$} & \multirow{2}{*}{$\begin{array}{l}\text { Negative Margin } \\
(\mathrm{N}=3,475)\end{array}$} & \multirow{2}{*}{$\begin{array}{l}\text { Positive Margin } \\
(\mathrm{N}=1,446)\end{array}$} & \multicolumn{2}{|c|}{ Multivariable Logistic Regression } \\
\hline & & & & OR $(95 \% \mathrm{Cl})$ & $P$ Value \\
\hline \multicolumn{6}{|l|}{ Age, y } \\
\hline$<65$ & $2,642(54 \%)$ & $1,885(54 \%)$ & $757(52 \%)$ & Ref & Ref \\
\hline $65-74$ & $1,697(35 \%)$ & $1,200(35 \%)$ & $497(34 \%)$ & $0.949(0.805-1.118)$ & .530 \\
\hline$>74$ & $582(12 \%)$ & $390(11 \%)$ & $192(13 \%)$ & $1.026(0.821-1.281)$ & .824 \\
\hline \multicolumn{6}{|l|}{ Sex } \\
\hline Male & $2,613(53 \%)$ & $1,784(51 \%)$ & $829(57 \%)$ & Ref & Ref \\
\hline \multicolumn{6}{|l|}{ Race } \\
\hline White & $4,271(87 \%)$ & $3,002(86 \%)$ & $1,269(88 \%)$ & Ref & Ref \\
\hline Black & $497(10 \%)$ & $358(10 \%)$ & $139(10 \%)$ & $1.057(0.868-1.288)$ & .581 \\
\hline Asian & $98(2 \%)$ & $72(2 \%)$ & $26(2 \%)$ & $0.903(0.591-1.379)$ & .636 \\
\hline Other & $55(1 \%)$ & $43(1 \%)$ & $12(1 \%)$ & $1.013(0.581-1.767)$ & .964 \\
\hline \multicolumn{6}{|c|}{ Charlson-Deyo score ${ }^{b}$} \\
\hline 0 & $2,693(55 \%)$ & $1,937(56 \%)$ & $756(52 \%)$ & Ref & Ref \\
\hline 1 & $1,653(34 \%)$ & $1,135(33 \%)$ & $518(36 \%)$ & $1.123(0.987-1.278)$ & .079 \\
\hline \multicolumn{6}{|l|}{ Insurance type } \\
\hline Medicaid & $317(6 \%)$ & $216(6 \%)$ & $101(7 \%)$ & Ref & Ref \\
\hline Private & $2,076(42 \%)$ & $1,495(43 \%)$ & $581(40 \%)$ & $1.005(0.784-1.289)$ & .968 \\
\hline Medicare & $2,253(46 \%)$ & $1,572(45 \%)$ & $681(47 \%)$ & $1.123(0.854-1.477)$ & .407 \\
\hline Uninsured & $128(3 \%)$ & $88(3 \%)$ & $40(3 \%)$ & $0.968(0.632-1.480)$ & .879 \\
\hline Other & $147(3 \%)$ & $104(3 \%)$ & $43(3 \%)$ & $1.028(0.683-1.548)$ & .895 \\
\hline \multicolumn{6}{|l|}{ Annual income } \\
\hline$<\$ 63,000$ & $3,556(72 \%)$ & $2,496(72 \%)$ & $1,060(73 \%)$ & Ref & Ref \\
\hline$\geq \$ 63,000$ & $1,310(27 \%)$ & $940(27 \%)$ & $370(26 \%)$ & $0.759(0.662-0.870)$ & $<.001$ \\
\hline Not recorded & $55(1 \%)$ & $39(1 \%)$ & $16(1 \%)$ & - & - \\
\hline \multicolumn{6}{|l|}{ Facility type } \\
\hline Academic & $1,277(26 \%)$ & $927(27 \%)$ & $350(24 \%)$ & Ref & Ref \\
\hline Nonacademic & $3,584(73 \%)$ & $2,503(72 \%)$ & $1,081(75 \%)$ & $1.242(1.085-1.422)$ & .002 \\
\hline Not recorded & $60(1 \%)$ & $45(1 \%)$ & $15(1 \%)$ & - & - \\
\hline \multicolumn{6}{|c|}{ Distance to treating facility, miles } \\
\hline$\leq 20$ & $3,509(71 \%)$ & $2,494(72 \%)$ & $1,015(70 \%)$ & Ref & Ref \\
\hline \multicolumn{6}{|l|}{ Year of diagnosis } \\
\hline $2004-2008$ & $1,711(35 \%)$ & $1,207(35 \%)$ & $504(35 \%)$ & Ref & Ref \\
\hline $2009-2014$ & $3,210(65 \%)$ & $2,268(65 \%)$ & $942(65 \%)$ & $0.867(0.765-0.983)$ & .026 \\
\hline
\end{tabular}

Percentages may not add up to $100 \%$ due to rounding.

Abbreviations: CRT, chemoradiotherapy; NOS, not otherwise specified; NSCLC, non-small cell lung cancer; OR, odds ratio.

astatistically significant $P$ values are in bold.

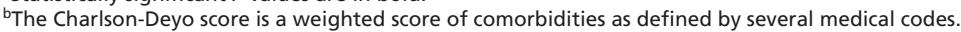


Concurrent vs Sequential CRT in NSCLC

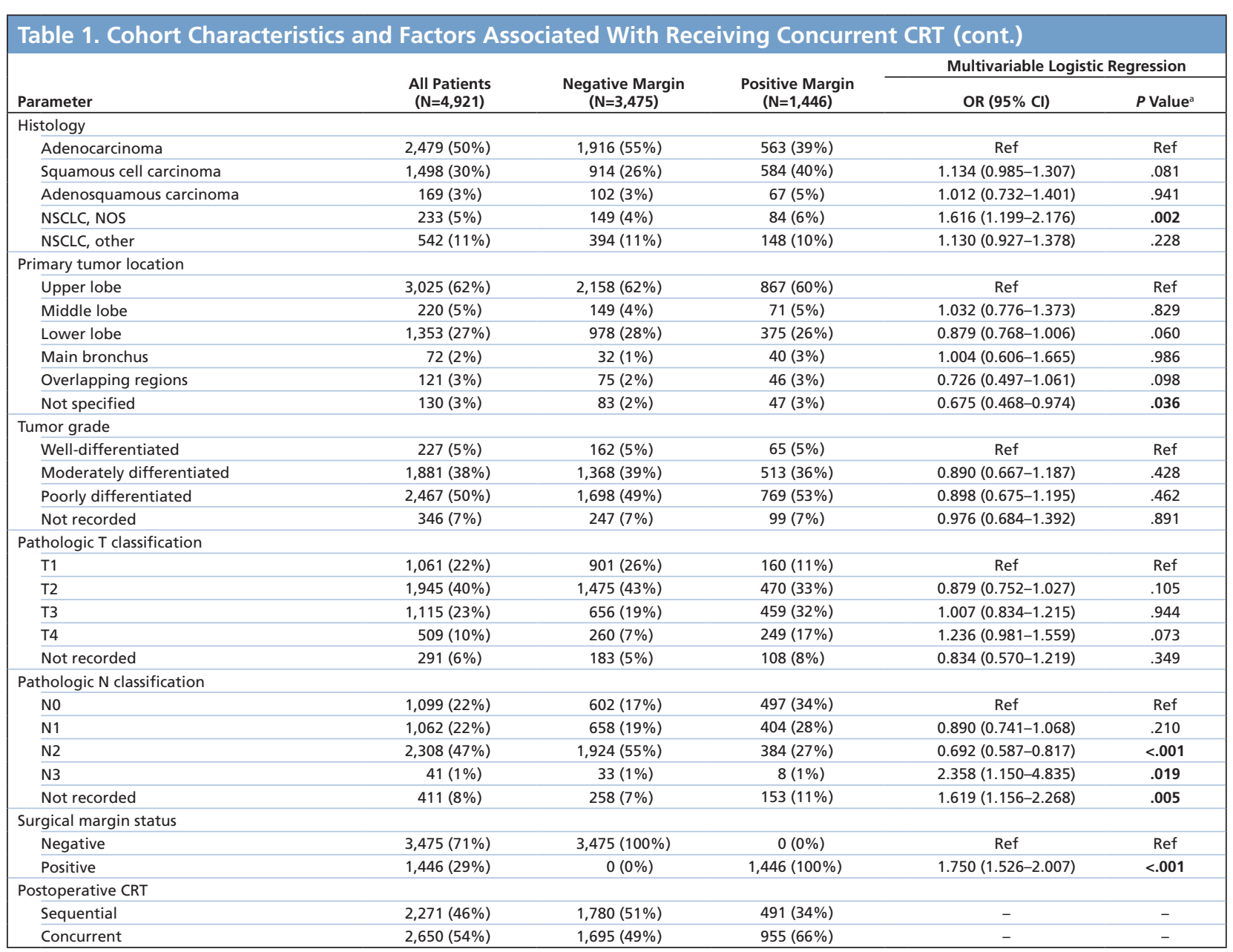

Percentages may not add up to $100 \%$ due to rounding.

Abbreviations: CRT, chemoradiotherapy; NOS, not otherwise specified; NSCLC, non-small cell lung cancer; OR, odds ratio.

astatistically significant $P$ values are in bold.

${ }^{\mathrm{b}}$ The Charlson-Deyo score is a weighted score of comorbidities as defined by several medical codes.

to avoid potential bias from many-to-one matching. Standardized differences were assessed to ensure balance between each of the variables included in calculating the propensity score to the matched cohorts, with a value $<0.1$ signifying an inconsequential imbalance. ${ }^{33}$ Pearson chi-square test was subsequently performed between the matched cohorts to confirm balance among the variable. Survival rates were then compared between the matched groups using the log-rank test.

\section{Results}

A complete flow diagram of patient selection is provided in supplemental eFigure 1 (available with this article at JNCCN.org). A total of 4,921 patients met study analysis criteria (Table 1). Of these, 3,475
(71\%) were $\mathrm{M}$ - and 1,446 (29\%) were $\mathrm{M}+; 2,271$ (46\%) received sCRT and 2,650 (54\%) underwent cCRT. Multivariable logistic regression analysis revealed that independent predictors of cCRT delivery included lower income, treatment at a nonacademic facility, diagnosis at earlier periods (2004-2008), histology of NSCLC not otherwise specified, and M+ disease $(P<.05$ for all $)$. The association with pathologic nodal classification is more difficult to interpret; with $\mathrm{pNO}$ as the reference, patients with $\mathrm{pN} 2$ disease were less likely to receive cCRT $(P<.001)$, but the very few patients who were evidently $\mathrm{pN} 3$ more often underwent cCRT $(P=.019)$.

Median follow-up was 30 months (interquartile range, 17-52 months). In all patients, median OS for patients who underwent sCRT was 50 versus 37 months for cCRT $(P<.001)$ (supplemental 
eFigure 2A. When separating these patients by margin status, sCRT displayed a higher OS in the M- (55 vs 40 months; $\mathrm{P}<.001$ ) and $\mathrm{M}+$ groups (36 vs 31 months; $P=.011$ ) (Figure 2A,B). Following PSM (supplemental eTables 1-3), these findings persisted among all patients (50 vs 39 months; $P=.001$; supplemental eFigure $2 \mathrm{~B}$ ) and in the $\mathrm{M}-$ group (55 vs 40 months; $P<.001$; Figure $2 \mathrm{C}$ ), but showed equivalence in the $\mathrm{M}+$ group (36 vs 33 months; $P=.745$; Figure 2D).

Given that not all patients with $\mathrm{M}+$ disease had available data on extent of resection, when substratifying them according to resection status and evaluating sCRT versus cCRT, both groups experienced similar OS in R1 (38 vs 37 months; $P=.368$ ) and $\mathrm{R} 2$ resections ( 25 vs 21 months; $P=.553$ ) (Figure $3 A, B$ ). These populations, namely the patients with R2 resections, were too small to reliably undergo PSM.

When analyzing the sCRT subset only, patients who received chemotherapy followed by RT experienced improved OS compared with those receiving RT followed by chemotherapy (53 vs 39 months; $P=.002$; Figure 3C). Following PSM (supplemental eTable 4), statistical equipoise remained between groups (46 vs 40 months; $P=.229$; Figure 3D).

In the overall cohort, there were several predictors of OS on univariate analysis (Table 2). After multivariate adjustment for potential confounding factors (Table 2), factors independently associated with poorer OS included advancing age, male sex, high comorbidity index, Medicaid insurance, treatment at a nonacademic facility and at earlier periods (2004-2008), adenosquamous histology, differentiation status, lower lobe location, $\mathrm{T}$ and $\mathrm{N}$ classification, surgical margin status, and receipt of cCRT $(P<.05$ for all).

\section{Discussion}

Our study of a contemporary national database most notably demonstrates that sCRT is associated with improved outcomes for patients with $\mathrm{M}$ - disease, and statistical equipoise for those with $\mathrm{M}+$ disease. Additionally, sCRT performed in a chemotherapy-first manner produced statistically equivalent survival as administering RT-first. Collectively, these hypothesisgenerating data do not imply causation (as discussed further) and should ideally be tested prospectively, but do illustrate comparative outcomes between sCRT and cCRT (and sequencing of sCRT) for the first
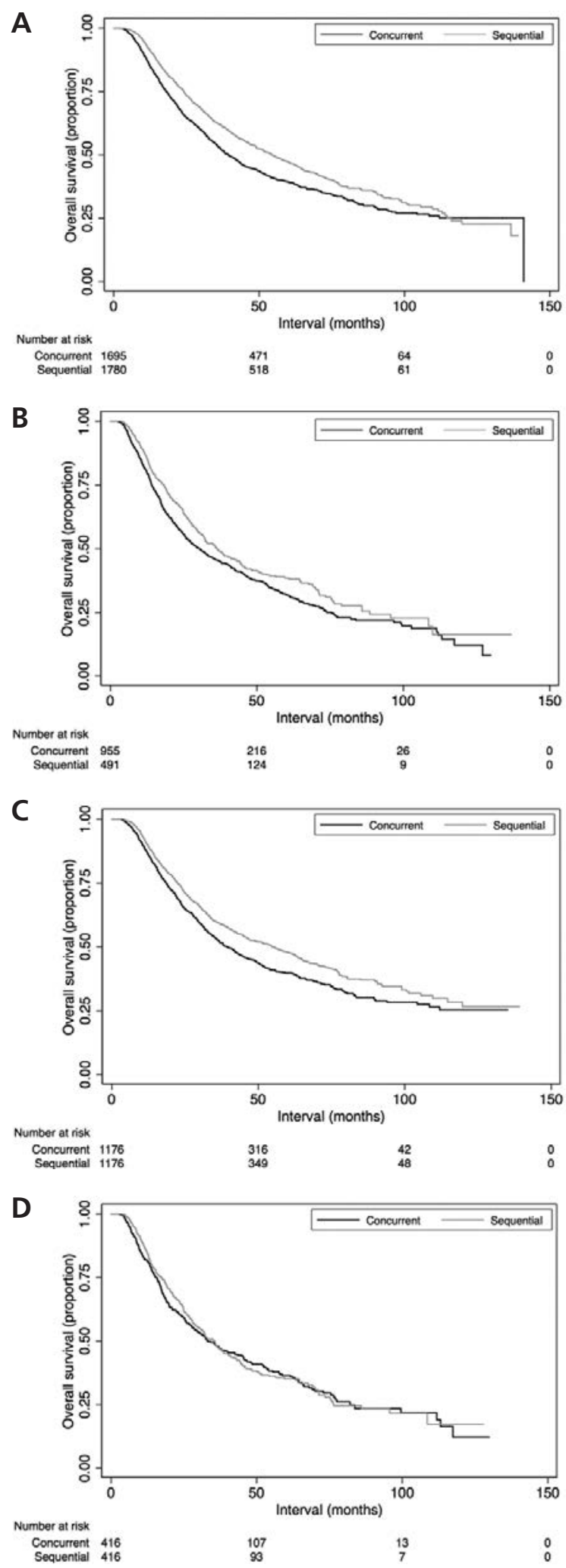

Figure 1. Kaplan-Meier overall survival curves comparing sequentia chemoradiotherapy (gray) versus concurrent chemoradiotherapy (black) in patients with (A) margin-negative disease and (B) marginpositive disease, and in propensity score-matched patients with (C) margin-negative disease and (D) margin-positive disease. 

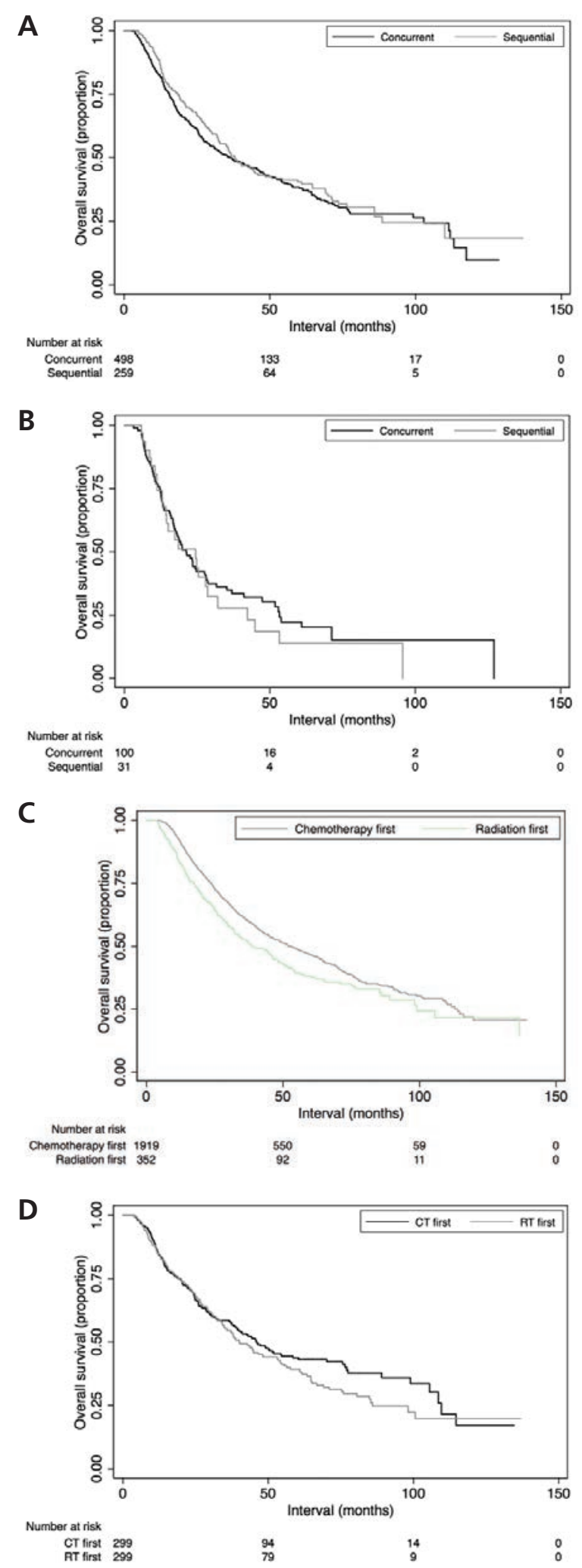

Figure 2. Kaplan-Meier overall survival curves comparing sequential chemoradiotherapy versus concurrent chemoradiotherapy in patients with (A) R1 resection and (B) R2 resection. Comparison of the sequential chemoradiotherapy cohort with receipt of (C) chemotherapy-first versus radiotherapy-first, and (D) after propensity score matching. time in a large population. To this extent, although the standard of care from prospective data supports adjuvant chemotherapy in both $\mathrm{pN} 1$ and $\mathrm{pN} 2$ disease (with additional RT in the latter), this study does not support the routine administration of cCRT.

In the absence of prospective data, it is readily acknowledged that retrospective selection biases may limit interpretation of this work. Notably, the cCRT group consisted of higher-risk disease (illustrating adherence to national guidelines), thus likely necessitating more aggressive therapy. These patients may have also likely received suboptimal chemotherapy doses if concurrent RT was delivered. PSM is a powerful tool to control for many of these biases, but only the variables available in the NCDB can be controlled. Although equipoise between both groups was demonstrated for $\mathrm{M}+$ disease, it is entirely possible that cCRT offers a real benefit to higher-risk patients (as observed by examining both R1 and R2 subgroups). However, that benefit is not enough to overcome multiple poor-prognostic factors when comparing to the sCRT group. A converse argument, however, is that delivering aggressive cCRT after lung resection may incur substantially more treatment-related morbidities, some of which may predispose toward earlier mortality, and that the increased toxicity from cCRT could diminish oncologic benefit (potentially even in the higher-risk patient population). Because the NCDB does not record other end points such as locoregional control, cancer-specific survival, or toxicities, it is unclear whether OS differences are cancer-related or morbidity-related. There is less reason to believe both groups experienced similar postoperative or 30-day mortality, given the similar initial slopes of the Kaplan-Meier curves in both groups, without a drastic decline in either group. Nevertheless, single- or multi-institutional data may be able to provide further insight, albeit at the cost of much smaller sample sizes. For instance, Kim et $\mathrm{al}^{34}$ demonstrated an increase in locoregional recurrence-free survival, but no differences in OS, with cCRT in M- cases $(n=68)$.

Likewise, the finding of statistically similar OS for chemotherapy-first and RT-first sCRT can be biased in either direction, especially in the absence of locoregional control as an end point in the NCDB. A major shortcoming of the $\mathrm{NCDB}$ is the absence of information on number of received chemotherapy cycles; although all patients received full-dose RT, those who received initial RT may not have tolerated optimal postoperative chemotherapy, thus compromising outcomes. This 
group may also have had larger-volume residual disease and/or rapid postoperative recurrence, neither of which is captured by the NCDB. However, the counterargument is the principal rationale for why chemotherapy is most commonly delivered first: namely, that virtually all postoperative patients who warrant combined-modality therapy are at high risk of distant failure, for which early chemotherapy administration is most necessary.

Based on these unavoidable biases in this and other similar NCDB studies, ${ }^{5,6}$ we posit a conservative interpretation of these data: there may not be a benefit to routinely delivering CCRT in patients with $\mathrm{M}-$ and $\mathrm{M}+$ disease, but well-selected patients may very well benefit from this approach. It is more intuitive that the relative benefit to concurrent therapy is greater with the larger amount of postoperative disease remaining. Although the NCDB does not code for size/volume of gross residual disease, it is still reasonable to consider cCRT or RT-first sCRT for larg- er-volume gross residual disease, or potentially even in patients with rapid growth following surgery. Although, most commonly chemotherapy was administered before PORT in patients undergoing sCRT, select patients may very well have an initially higher risk of local/regional failure instead of distant failure. ${ }^{14}$ We recommend that decision-making should continue to be made judiciously, while assessing the balance between oncologic benefit and potential adverse events. Factors such as age, performance status, and tolerance of concurrent therapy (along with tolerance of surgery and/or any postoperative events) are essential to consider when determining optimal postoperative management, and despite these data, we highly advocate for individualized management in this circumstance.

Nevertheless, it is also interesting to evaluate factors and trends associated with cCRT versus sCRT delivery. Based on results from multivariable

\begin{tabular}{|c|c|c|c|c|}
\hline \multirow[b]{2}{*}{ Parameter } & \multicolumn{2}{|c|}{ Univariate } & \multicolumn{2}{|c|}{ Multivariate } \\
\hline & HR $(95 \% \mathrm{Cl})$ & $P$ Value $^{\mathrm{a}}$ & HR $(95 \% \mathrm{Cl})$ & $P$ Value $^{\mathrm{a}}$ \\
\hline \multicolumn{5}{|l|}{ Age, y } \\
\hline$<65$ & Ref & Ref & Ref & Ref \\
\hline $65-74$ & $1.323(1.219-1.437)$ & $<.001$ & $1.312(1.177-1.462)$ & $<.001$ \\
\hline$>74$ & $1.598(1.426-1.790)$ & $<.001$ & $1.543(1.342-1.774)$ & $<.001$ \\
\hline \multicolumn{5}{|l|}{ Sex } \\
\hline Male & Ref & Ref & Ref & Ref \\
\hline Female & $0.761(0.706-0.821)$ & $<.001$ & $0.782(0.724-0.846)$ & $<.001$ \\
\hline \multicolumn{5}{|l|}{ Race } \\
\hline White & Ref & Ref & Ref & Ref \\
\hline Black & $0.948(0.835-1.077)$ & .415 & $1.041(0.914-1.187)$ & .544 \\
\hline Asian & $0.682(0.503-0.925)$ & .014 & $0.789(0.580-1.075)$ & .134 \\
\hline Other & $0.833(0.562-1.236)$ & .364 & $0.843(0.567-1.253)$ & .398 \\
\hline \multicolumn{5}{|c|}{ Charlson-Deyo score ${ }^{b}$} \\
\hline 0 & Ref & Ref & Ref & Ref \\
\hline 1 & $1.121(1.031-1.218)$ & .007 & $1.084(0.996-1.179)$ & .061 \\
\hline$\geq 2$ & $1.236(1.214-1.527)$ & $<.001$ & $1.296(1.153-1.457)$ & $<.001$ \\
\hline \multicolumn{5}{|l|}{ Insurance type } \\
\hline Medicaid & Ref & Ref & Ref & Ref \\
\hline Private & $0.820(0.697-0.964)$ & .017 & $0.778(0.660-0.918)$ & .003 \\
\hline Medicare & $1.113(0.948-1.306)$ & .190 & $0.814(0.679-0.975)$ & .026 \\
\hline Uninsured & $1.075(0.815-1.419)$ & .608 & $1.085(0.821-1.434)$ & .566 \\
\hline Other & $1.041(0.900-1.357)$ & .767 & $0.941(0.720-1.230)$ & .656 \\
\hline \multicolumn{5}{|l|}{ Annual income } \\
\hline$<\$ 63,000$ & Ref & Ref & - & - \\
\hline$\geq \$ 63,000$ & $0.921(0.845-1.040)$ & .063 & - & - \\
\hline \multicolumn{5}{|l|}{ Facility type } \\
\hline Academic & Ref & Ref & Ref & Ref \\
\hline Nonacademic & $1.163(1.065-1.271)$ & .001 & $1.143(1.044-1.252)$ & .004 \\
\hline \multicolumn{5}{|c|}{ Distance to treating facility, miles } \\
\hline$\leq 20$ & Ref & Ref & - & - \\
\hline$>20$ & $0.996(0.915-1.084)$ & .930 & - & - \\
\hline \multicolumn{5}{|l|}{ Year of diagnosis } \\
\hline $2004-2008$ & Ref & Ref & Ref & Ref \\
\hline 2009-2014 & $0.863(0.798-0.934)$ & $<.001$ & $0.876(0.808-0.950)$ & .001 \\
\hline
\end{tabular}

Abbreviations: CRT, chemoradiotherapy; HR, hazard ratio; NOS, not otherwise specified; NSCLC, non-small cell lung cancer.

${ }^{\text {a }}$ Statistically significant $P$ values are in bold.

${ }^{\mathrm{b}}$ The Charlson-Deyo score is a weighted score of comorbidities as defined by several medical codes. 
Concurrent vs Sequential CRT in NSCLC

\begin{tabular}{|c|c|c|c|c|}
\hline \multirow[b]{2}{*}{ Parameter } & \multicolumn{2}{|c|}{ Univariate } & \multicolumn{2}{|c|}{ Multivariate } \\
\hline & HR $(95 \% \mathrm{Cl})$ & $P$ Value $^{\mathrm{a}}$ & HR $(95 \% \mathrm{Cl})$ & $P$ Value ${ }^{a}$ \\
\hline \multicolumn{5}{|l|}{ Histology } \\
\hline Adenocarcinoma & Ref & Ref & Ref & Ref \\
\hline Squamous cell carcinoma & $1.234(1.133-1.345)$ & $<.001$ & $1.063(0.969-1.165)$ & .196 \\
\hline Adenosquamous carcinoma & $1.468(1.208-1.784)$ & $<.001$ & $1.314(1.080-1.600)$ & .006 \\
\hline NSCLC, NOS & $1.281(1.084-1.512)$ & .004 & $1.074(0.903-1.277)$ & .420 \\
\hline NSCLC, other & $1.079(0.951-1.223)$ & .238 & $1.029(0.904-1.172)$ & .663 \\
\hline \multicolumn{5}{|l|}{ Primary tumor location } \\
\hline Upper lobe & Ref & Ref & Ref & Ref \\
\hline Middle lobe & $1.112(0.927-1.334)$ & .254 & $1.138(0.947-1.366)$ & .168 \\
\hline Lower lobe & $1.130(1.037-1.231)$ & .005 & $1.113(1.019-1.215)$ & .017 \\
\hline Main bronchus & $1.151(0.847-1.564)$ & .369 & $0.915(0.670-1.249)$ & .576 \\
\hline Overlapping regions & $1.182(0.944-1.479)$ & .145 & $0.978(0.780-1.228)$ & .851 \\
\hline Not specified & $0.950(0.748-1.207)$ & .674 & $0.894(0.701-1.139)$ & .363 \\
\hline \multicolumn{5}{|l|}{ Tumor grade } \\
\hline Well-differentiated & Ref & Ref & Ref & Ref \\
\hline Moderately differentiated & $1.333(1.088-1.633)$ & .005 & $1.253(1.021-1.537)$ & .031 \\
\hline Poorly differentiated & $1.397(1.144-1.707)$ & .001 & $1.309(1.069-1.603)$ & .009 \\
\hline Not recorded & $1.401(1.103-1.779)$ & .006 & $1.272(0.975-1.588)$ & .080 \\
\hline \multicolumn{5}{|l|}{ Pathologic T classification } \\
\hline $\mathrm{T} 1$ & Ref & Ref & Ref & Ref \\
\hline $\mathrm{T} 2$ & $1.200(1.081-1.333)$ & .001 & $1.167(1.049-1.198)$ & $<.001$ \\
\hline $\mathrm{T} 3$ & $1.244(1.106-1.400)$ & $<.001$ & $1.314(1.156-1.492)$ & $<.001$ \\
\hline $\mathrm{T} 4$ & $1.663(1.450-1.807)$ & $<.001$ & $1.647(1.427-1.901)$ & $<.001$ \\
\hline Not recorded & $1.665(1.415-1.960)$ & $<.001$ & $1.574(1.255-1.976)$ & $<.001$ \\
\hline \multicolumn{5}{|l|}{ Pathologic N classification } \\
\hline No & Ref & Ref & Ref & Ref \\
\hline $\mathrm{N} 1$ & $1.254(1.118-1.408)$ & $<.001$ & $1.397(1.238-1.576)$ & $<.001$ \\
\hline N2 & $1.156(1.046-1.279)$ & .005 & $1.510(1.351-1.688)$ & $<.001$ \\
\hline N3 & $1.998(1.375-2.904)$ & $<.001$ & $2.363(1.616-3.457)$ & $<.001$ \\
\hline Not recorded & $1.468(1.270-1.700)$ & $<.001$ & $1.192(1.058-1.580)$ & .012 \\
\hline \multicolumn{5}{|l|}{ Surgical margin status } \\
\hline Negative & Ref & Ref & Ref & Ref \\
\hline Positive & $1.373(1.267-1.488)$ & $<.001$ & $1.272(1.167-1.387)$ & $<.001$ \\
\hline \multicolumn{5}{|l|}{ Postoperative CRT } \\
\hline Sequential & Ref & Ref & Ref & Ref \\
\hline Concurrent & $1.298(1.203-1.401)$ & $<.001$ & $1.239(1.144-1.340)$ & $<.001$ \\
\hline
\end{tabular}

Abbreviations: CRT, chemoradiotherapy; HR, hazard ratio; NOS, not otherwise specified; NSCLC, non-small cell lung cancer.

aStatistically significant $P$ values are in bold.

${ }^{b}$ The Charlson-Deyo score is a weighted score of comorbidities as defined by several medical codes.

logistic regression analysis, cCRT seems to be declining in more recent periods (2009-2014), but was still more likely used at nonacademic centers. This finding could relate to the more recent publication of small series, ${ }^{34}$ and to the potentially higher receptivity to evidence-based management at academic centers. Lastly, because the postoperative CRT cohort mostly comprises pN2 disease, available evidence ${ }^{3}$ has more commonly used sCRT for these circumstances, which was also observed herein. It was, however, somewhat odd that $\mathrm{pN} 3$ cases were more likely to receive cCRT, because surgical procedures do not routinely evaluate these areas.

The independent association between treatment at an academic facility and OS on multivariate analysis has far-reaching implications on patient counseling and management by oncologists and referring providers. There are several potential reasons for this, including greater multimodality coordination, streamlined diagnostic processes, technical expertise, ancillary support staff for close toxicity monitoring, and potentially the availability of salvage therapies (or clinical trials). Nevertheless, this finding may impact any case of postoperative CRT and could warrant revisions in patterns of patient education.

Although the NCDB provides a unique platform with which to study this important clinical question, the present investigation has some additional limitations to those previously discussed herein. First, the NCDB does not keep track of several other factors, including chemotherapy cycles/agents, performance/functional status, lymph node ratio, lymphovascular invasion, or nature of preoperative workup (including brain MRI and PET staging). It also offers very limited or no information on RT field design, treatment volumes, or techniques. Information in technique is especially important because advanced techniques such as intensity-modulated RT can potentially reduce toxicity risk in the postoperative 
Verma et al

setting. Second, no information is provided regarding surgeon experience, reexcision rates, and toxicity-related deaths. Third, the NCDB does not allow for an assessment of subsequent lines of treatment (eg, reirradiation, further systemic and/or targeted therapy), which could influence OS. Nevertheless, the known shortcomings of a national, large-volume database do not undermine the necessity for further prospective investigation; the ongoing LungART trial will likely help address several unresolved PORT-related controversies (ClinicalTrials. gov identifier: NCT00410683.

\section{Conclusions}

This is the largest study to date evaluating sCRT versus cCRT in the postoperative setting. There seems to be no noticeable benefit to routinely delivering cCRT in $\mathrm{M}-$ or $\mathrm{M}+$ disease, and sequencing sCRT with either chemotherapy-first or RT-first seemed to

\section{References}

1. Ettinger DS, Wood DE, Aisner DL, et al. NCCN Guidelines for Non-Small Cell Lung Cancer. Version 8.2017. Accessed September 21, 2017. To view the most recent version of these guidelines, visit NCCN.org.

2. PORT Meta-analysis Trialists Group. Postoperative radiotherapy for non-small cell lung cancer. Cochrane Database Syst Rev 2005;18:CD002142.

3. Douillard JY, Rosell R, De Lena M, et al. Impact of postoperative radiation therapy on survival in patients with complete resection and stage I, II, or IIIA non-small-cell lung cancer treated with adjuvant chemotherapy: the Adjuvant Navelbine International Trialist Association (ANITA) randomized trial. Int J Radiat Oncol Biol Phys 2008;72:695-701.

4. Lally BE, Zelterman D, Colasanto JM, et al. Postoperative radiotherapy for stage II or III non-small-cell lung cancer using the Surveillance, Epidemiology, and End Results database. J Clin Oncol 2006;24:2998-3006.

5. Robinson CG, Patel AP, Bradley JD, et al. Postoperative radiotherapy for pathologic N2 non-small-cell lung cancer treated with adjuvant chemotherapy: a review of the National Cancer Data Base. J Clin Oncol 2015;33:870-876.

6. Wang $\mathrm{EH}$, Corso $\mathrm{CD}$, Rutter $\mathrm{CE}$, et al. Postoperative radiation therapy is associated with improved overall survival in incompletely resected stage II and III non-small-cell lung cancer. J Clin Oncol 2015;33:2727-2734.

7. Hancock JG, Rosen JE, Antonicelli A, et al. Impact of adjuvant treatment for microscopic residual disease after non-small cell lung cancer surgery. Ann Thorac Surg 2015;99:406-413.

8. Keller $\mathrm{SM}$, Adak $\mathrm{S}$, Wagner $\mathrm{H}$, et al. A randomized trial of postoperative adjuvant therapy in patients with completely resected stage II or IIIA nonsmall-cell lung cancer. Eastern Cooperative Oncology Group. N Engl J Med 2000;343:1217-1222.

9. Curran WJ Jr, Paulus R, Langer CJ, et al. Sequential vs. concurrent chemoradiation for stage III non-small cell lung cancer: randomized phase III trial RTOG 9410. J Natl Cancer Inst 2011;103:1452-1460.

10. Auperin A, Le Pechoux C, Rolland E, et al. Meta-analysis of concomitant versus sequential radiochemotherapy in locally advanced non-small-cell lung cancer. J Clin Oncol 2010;28:2181-2190.

11. Bradley JD, Paulus R, Graham MV, et al. Phase II trial of postoperative adjuvant paclitaxel/carboplatin and thoracic radiotherapy in resected stage II and IIIA non-small-cell lung cancer: promising long-term results of the Radiation Therapy Oncology Group--RTOG 9705. J Clin Oncol 2005;23:3480-3487.

12. Feigenberg SJ, Hanlon AL, Langer C, et al. A phase II study of concurrent carboplatin and paclitaxel and thoracic radiotherapy for completely resected stage II and IIIA non-small cell lung cancer. J Thorac Oncol 2007;2:287-292.

13. Kepka L, Socha J, Rucinska M, et al. Sequencing postoperative radiotherapy and adjuvant chemotherapy in non-small cell lung cancer: unanswered questions on the not evidence-based approach. J Thorac Dis 2016;8:1381-1385.

14. Lee HW, Noh OK, Oh YT, et al. Radiation therapy-first strategy after surgery with or without adjuvant chemotherapy in stage IIIA-N2 non-small cell lung cancer. Int J Radiat Oncol Biol Phys 2016;94:621-627.

15. Stahl JM, Corso CD, Verma V, et al. Trends in stereotactic body radiation therapy for stage I small cell lung cancer. Lung Cancer 2017;103:11-16.

16. Haque W, Verma V, Butler EB, Teh BS. Patterns of care and outcomes of multiagent versus single-agent chemotherapy as part of multimodal management of low grade glioma. J Neurooncol 2017;133:369-375.
17. Haque W, Verma V, Butler EB, Teh BS. National practice patterns and outcomes for T4b urothelial cancer of the bladder [published online September 6, 2017]. Clin Genitourin Cancer. doi:10.1016/j.clgc.2017.08.013

18. Moreno AC, Verma V, Hofstetter WL, et al. Patterns of care and treatment outcomes of elderly patients with stage I esophageal cancer: analysis of the National Cancer Data Base. J Thorac Oncol 2017;12:1152-1160.

19. McMillan MT, Ojerholm E, Verma V, et al. Radiation treatment time and overall survival in locally advanced non-small cell lung cancer. Int J Radiat Oncol Biol Phys 2017;98:1142-1152.

20. Verma V, Ryckman JM, Simone CB II, Lin C. Patterns of care and outcomes with the addition of chemotherapy to radiation therapy for stage I nasopharyngeal cancer. Acta Oncol 2018;57:257-261.

21. Verma V, Ahern CA, Berlind CG, et al. National Cancer Data Base report on pneumonectomy versus lung-sparing surgery for malignant pleural mesothelioma. J Thorac Oncol 2017;12:1704-1714.

22. Haque W, Verma V, Fakhreddine M, et al. Addition of chemotherapy to definitive radiotherapy for IB1 and IIA1 cervical cancer: analysis of the National Cancer Data Base. Gynecol Oncol 2017;144:28-33.

23. Verma V, McMillan MT, Grover S, et al. Stereotactic body radiation therapy and the influence of chemotherapy on overall survival for large ( $\geq 5$ centimeter non-small cell lung cancer. Int J Radiat Oncol Biol Phys 2017;97:146-154.

24. Haque W, Verma V, Butler EB, Teh BS. Radical cystectomy versus chemoradiation for muscle-invasive bladder cancer: impact of treatment facility and sociodemographics. Anticancer Res 2017;37:5603-5608.

25. Haque W, Verma V, Butler EB, Teh BS. Definitive chemoradiation at high volume facilities is associated with improved survival in glioblastoma. J Neurooncol 2017;135:173-181.

26. Amini A, Jones BL, McDermott JD, et al. Survival outcomes with concurrent chemoradiation for elderly patients with locally advanced head and neck cance according to the National Cancer Data Base. Cancer 2016;122:1533-1543.

27. Varlotto JM, Yao AN, DeCamp MM, et al. Nodal stage of surgically resected non-small cell lung cancer and its effect on recurrence patterns and overall survival. Int J Radiat Oncol Biol Phys 2015;91:765-773.

28. El-Sherif A, Fernando HC, Santos R, et al. Margin and local recurrence after sublobar resection of non-small cell lung cancer. Ann Surg Oncol 2007;14:2400-2405.

29. Gomez DR, Komaki R. Postoperative radiation therapy for non-small cell lung cancer and thymic malignancies. Cancers (Basel) 2012;4:307-322.

30. Austin PC. Statistical criteria for selecting the optimal number of untreated subjects matched to each treated subject when using many-to-one matching on the propensity score. Am J Epidemiol 2010; 172:1092-1097.

31. Rosenbaum PR, Rubin DB. The central role of the propensity score in observational studies for causal effects. Biometrika 1983;70:15.

32. Austin PC, Gootendorst P, Anderson GM. A comparison of the ability of different propensity score models to balance measured variables between treated and untreated subjects: a Monte Carlo study. Stat Med 2007;26:734-753.

33. Austin PC. Balance diagnostics for comparing the distribution of baseline covariates between treatment groups in propensity-score matched samples. Stat Med 2009;28:3083-3107.

34. Kim HI, Noh OK, Oh YT, et al. Comparison of concurrent chemoradiotherapy versus sequential radiochemotherapy in patients with completely resected nonsmall cell lung cancer. Radiat Oncol J 2016;34:202-208. 